\title{
Copper(II) Coordination Compounds with Sterically Constraining Pyrenyl Nitronyl Nitroxide and Imino Nitroxide.
}

Rafael A. Allão Cassaro ${ }^{1,3 *}$, Jonathan R. Friedman ${ }^{2}$, Paul M. Lahti ${ }^{3}$

\section{$\underline{\text { Abstract }}$}

2-(1'-Pyrenyl)-4,4,5,5-tetramethyl-4,5-dihydro- $1 H$-imidazole-3-oxide-1-oxyl (PyrNN) and 2-(1'-pyrenyl)-4,4,5,5-tetramethyl-4,5-dihydro-1H-imidazole-1-oxyl (PyrIN) form pentacoordinate metal-radical complexes with $\mathrm{Cu}(\mathrm{hfac})_{2}: \quad\left[\mathrm{Cu}(\mathrm{hfac})_{2} \mathrm{PyrNN}\right]$ and $\left[\mathrm{Cu}(\mathrm{hfac})_{2} \mathrm{PyrIN}\right], \mathbf{1}$ and $\mathbf{2}$, respectively. In $\mathbf{1}$, one aminoxyl unit of PyrNN coordinates to $\mathrm{Cu}(\mathrm{II})$ in a distorted square pyramidal environment. In 2, an unusual example of monodentate $\mathrm{Cu}-\mathrm{N}$ coordination of the imino nitroxide, PyrIN, gives an environment intermediate between square pyramidal and trigonal bipyramid. Both complexes show novel close contacts of the pyrene $\pi$-electron cloud with the $\mathrm{Cu}(\mathrm{II})$ ion. Compound $\mathbf{1}$ has a particularly short $\mathrm{Cu}-\mathrm{O}(\mathrm{N})$ bond of $1.948 \AA$, giving strong intramolecular antiferromagnetic (AFM) spin-pairing and an absence of significant paramagnetic susceptibility response. The magnetic behavior of compound $\mathbf{2}$ indicates copper-radical intramolecular ferromagnetic exchange of $2 J=151 \mathrm{~cm}^{-1}$, and intermolecular AFM spin pairing of $2 J=-220 \mathrm{~cm}^{-1}$ due to close antiparallel contacts between non-coordinated $\mathrm{N}-\mathrm{O}$ units. EPR spectra for both complexes are silent at 293 and $77 \mathrm{~K}$. UB97D/6-31G(d) computations find strong antiferromagnetic $\left(2 J=-213 \mathrm{~cm}^{-1}\right)$ and ferromagnetic $\left(2 J=610 \mathrm{~cm}^{-1}\right)$ intramolecular metalradical exchange in $\mathbf{1}$ and $\mathbf{2}$, respectively in agreement with experimental results.

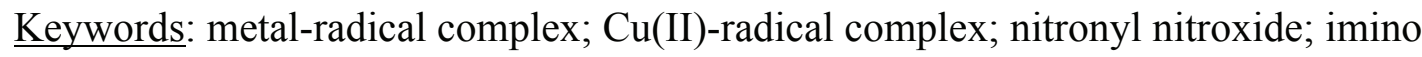
nitroxide; pyrene 


\section{Introduction.}

Metal-radical complexes have been subjected to intense scrutiny for over 30 years [16]. Part of the incentive for these studies is to understand their fundamental electronic behavior and magnetic properties, and to probe their possible technological use. Such molecule-based magnetic materials can be made using mild condition synthetic protocols, and they have much potential for combining multiple properties in one material, such as magnetic detectability and tunability, photo-switchability, and low-temperature processibility.

The synthetic strategies developed for making metal-radical complexes are strongly based on transition metal cation affinities for specific heteroatom coordination, including direct coordination of radical ligand (L) sites with high spin density, as in aminoxyl[1,5,6], verdazyls[7-8], thiazyls[9], triazinyl[10-11], nindigo[12], TCNE[13] and semiquinone radicals [14-15]. We have been interested in the additional role played by size-exclusion and steric effects on both primary structure of metal-radical materials, and on intermolecular packing effects that are so crucial to bulk magnetic behavior in molecule-based systems.

Recently, some of us (with others) reported [16-17] the synthesis and magnetostructural characterization of metal-radical complexes made with nitronyl nitroxide $(\mathrm{NN})$ radicals bearing polycyclic aromatic hydrocarbon $(\mathrm{PAH})$ substituents. Examples of this novel use of PAH-bearing NNs include both $\mathrm{ML}_{2}$ cluster and (ML) nelical chain complexes of 2-(1'-pyrenyl)-4,4,5,5-tetramethyl-4,5-dihydro- $1 H$-imidazole-3-oxide-1-oxyl (PyrNN) (Scheme 1). Such PAH's act as sterically substantial, rigid rotor units, but also influence intermolecular packing through motifs such as PAH $\pi$-stacking and formation of $\mathrm{C}-\mathrm{H}$ to $\pi$-cloud interactions. In addition, PAH's offer rich possibilities for additional property incorporation, such as tunable light absorption and other interactions with their large, polarizable $\pi$-clouds. Most notably, the $\mathrm{Co}(\mathrm{hfac})_{2}(\mathrm{ML})_{\mathrm{n}}$ helical-chain materials 
exhibit slow relaxation of magnetization of a strongly exchange coupled, single-chain magnet (SCM) material having high coercive field and high blocking temperatures [17-18].

As part of expanding the scope of PAH based radicals in metal-radical systems, we now report the synthesis and characterization of complexes formed by $\mathrm{Cu}(\mathrm{hfac})_{2}$ with $\mathrm{PyrNN}$ and 2-(1'-pyrenyl)-4,4,5,5-tetramethyl-4,5-dihydro-1 $H$-imidazole-1-oxyl (PyrIN). Two new molecular compounds $\left[\mathrm{Cu}(\mathrm{hfac})_{2} \mathrm{PyrNN}\right], \mathbf{1}$, and $\left[\mathrm{Cu}(\mathrm{hfac})_{2} \mathrm{PyrIN}\right], \mathbf{2}$, are pentacoordinated metal-radical complexes. Evidence is presented that the bulky pyrene unit plays an important role in determining both the molecular ligand spheres for these compounds, and in their intermolecular packing in the solid state.

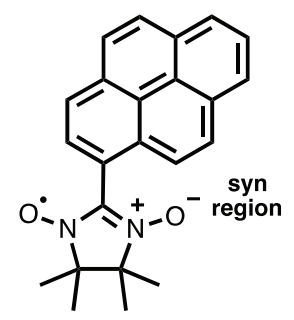

PyrNN<smiles>CC1(C)N=C(c2ccc3ccc4cccc5ccc2c3c45)N([O])C1(C)C</smiles>

PyriN<smiles>O=C(C=C(C(=O)C(F)(F)F)C(F)(F)F)C(F)(F)F</smiles>

hfac

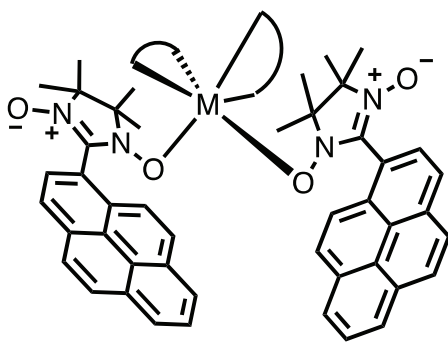

$\left[\mathrm{M}(\mathrm{hfac})_{2} \mathrm{~L}_{2}\right]$ cluster

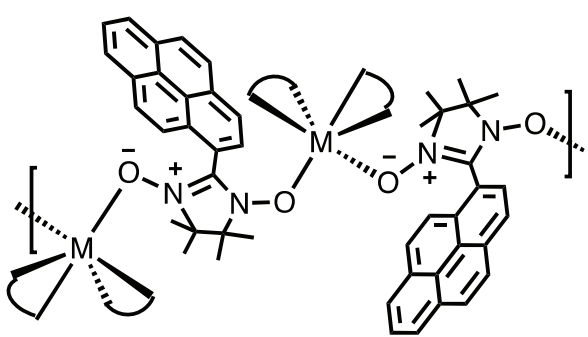

$\left[\mathrm{M}(\mathrm{hfac})_{2} \mathrm{~L}\right]_{\mathrm{n}}$ chain

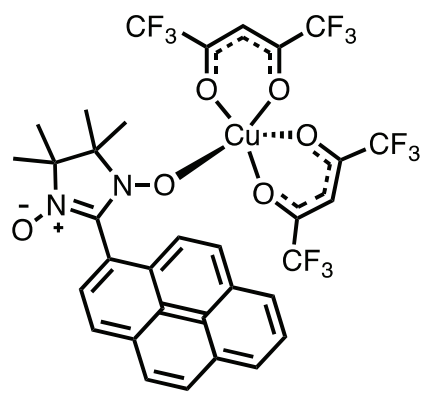

1

[Cu(hfac) ${ }_{2}$ (PyrNN)] \{this work\}

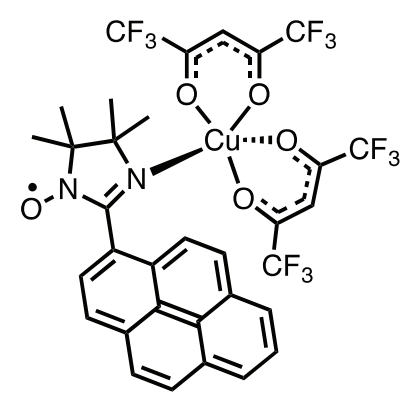

[Cu(hfac) ${ }_{2}($ PyrIN)] \{this work\}

Scheme 1. Polycyclic aromatic hydrocarbon (PAH) substituted radical units used in this work, and previous examples of their coordination complexes. In the middle structures, arcs represent hfac coordination, $L=$ PyrNN.

\section{Experimental}




\subsection{General Methods}

All reagents and solvents were purchased from commercial sources and used without further purification. Elemental analyses were performed by Micro-analysis, Inc. Infrared (IR) spectra were recorded using a Bruker Alpha FTIR spectrophotometer with attenuated total reflectance (ATR) accessory. The radicals PyrNN and PyrIN were synthesized according to previously described procedures [19]. Reflectance spectra were obtained using an Ocean Optics USB2000+ VIS-NIR spectrometer. Powder X-band electron paramagnetic resonance (EPR) spectra were obtained in quartz $4 \mathrm{~mm}$ O.D. tubes both at room temperature and at $77 \mathrm{~K}$ with a quartz finger dewar, using a Bruker Elexsys E500 spectrometer operating at $v_{0}=9.6 \mathrm{GHz}, 100 \mathrm{KHz}$ frequency modulation, $4 \mathrm{G}$ modulation amplitude.

\subsection{Synthesis of $\left[\mathrm{Cu}(\mathrm{hfac})_{2}(\mathrm{PyrNN})\right]$ (1)}

To a solution of $0.03 \mathrm{~g}\left(6.00 \times 10^{-5} \mathrm{~mol}\right)$ of $\left[\mathrm{Cu}(\mathrm{hfac})_{2}\right] \cdot \mathrm{H}_{2} \mathrm{O}$ dissolved in $17 \mathrm{~mL}$ of boiling anhydrous $n$-heptane, $0.021 \mathrm{~g}\left(6.00 \times 10^{-5} \mathrm{~mol}\right)$ of PyrNN was added with stirring. The reaction was stirred for $2 \mathrm{~min}$, then allowed to cool to room temperature. Black crystals were obtained by keeping the solution at $-20{ }^{\circ} \mathrm{C}$ for $24 \mathrm{~h}(0.013 \mathrm{~g}, 26 \%)$. Anal. Calc. for $\mathrm{C}_{33} \mathrm{H}_{23} \mathrm{CuF}_{12} \mathrm{~N}_{2} \mathrm{O}_{6}$ : C $47.46 \%$, H 2.78\%, N 3.35\%. Found: $\mathrm{C} 47.46 \%, \mathrm{H}$ 2.63\%, N 3.34\%. IR $\left(\mathrm{cm}^{-1}\right):$ 3142(w), 3133(w), 3052(w), 3005(w), 2988(w), 2959(w), 2931(w), 2872(w), 2860(w), 1654(m), 1640(s), 1603(m), 1596(m), 1551(m), 1527(m), 1477(m), 1456(m), 1394(m), 1385(w), 1374(w), 1350(w), 1333(m), 1320(w), 1310(w), 1254(s), 1197(s), 1181(s), 1142(s), 1105(s), 1088(s), 973(w), 955(w), 945(w), 906(w), 889(w), 878(w), 848(s), 817(m), 810(m), 797(s), 763(s), 744(m), 736(m), 714(m), 693(m), 676(s), 667(s), 649(m), 622(m), 589(s), 576(s), 561(w), 548(m), 528(m), 507(w), 483(m), 473(m), 456(m), 426(m), 415(w), 405(w), 394(w). A solid powder reflectance spectrum is given in supporting material Figure S1. 
To a solution of $0.050 \mathrm{~g}\left(1.00 \times 10^{-4} \mathrm{~mol}\right)$ of $\left[\mathrm{Cu}(\mathrm{hfac})_{2}\right] . \mathrm{H}_{2} \mathrm{O}$ dissolved in $10 \mathrm{~mL}$ of boiling anhydrous $n$-heptane, $0.034 \mathrm{~g}\left(1.00 \times 10^{-4} \mathrm{~mol}\right)$ of PyrIN was added with stirring. The reaction was stirred for $2 \mathrm{~min}$, then allowed to cool to room temperature. Black crystals were obtained by keeping the solution at $-20{ }^{\circ} \mathrm{C}$ for 20 days $(0.029 \mathrm{~g}$, 35\%). Anal. Calc. for $\mathrm{C}_{33} \mathrm{H}_{23} \mathrm{CuF}_{12} \mathrm{~N}_{2} \mathrm{O}_{5}$ : C 48.39\%, H 2.83\%, N 3.42\%. Found: C 48.42 \%, H $2.61 \%$, N $3.42 \%$. IR $\left(\mathrm{cm}^{-1}\right)$ : 3133(w), 3049(w), 2995(w), 2982(w), 2937(w), 2871(w), 1646(s), 1605(w), 1598(w), 1588(w), 1551(m), 1525(m), 1497(m), 1474(m, br), 1449(m), 1419(w), 1399(w), 1391(w), 1375(w), 1344(w), 1323(w), 1252(s), 1194(s), 1136(s), 1092(s), 1050(w), 999(w), 946(w), 892(w), 846(s), 827(m), 794(s), 761(m), 742(m), 718(m), 688(m), 663(s), 626(w), 581(s), 527(m), 513(w), 473(w), 457(w), 445(w), 421(w), 402(w), 382(w). A solid powder reflectance spectrum is given in supporting material Figure S2.

\subsection{Magnetic Measurements}

Dc-magnetic susceptibility measurements $\left(\chi=\right.$ magnetization $/$ field $=M / H=\mathrm{cm}^{3}$ $\mathrm{mol}^{-1}$ ) were carried out using a Quantum Design PPMS. Powder samples were placed in gelatin capsules for analysis and held in place with a plug of cotton. Magnetic data were corrected for contribution of the sample holder; sample diamagnetism corrections were estimated using Pascal's constants [20-21]. The magnetic data were fitted using the MagProp routine in the DAVE software suite [22].

\subsection{Crystallographic Studies}

Single crystal X-ray diffraction data for 1-2 were collected on a Bruker Kappa-CCD using graphite-monochromated $\operatorname{MoK}_{\alpha}$ radiation $(\lambda=0.71073 \AA)$. The unit cell parameters were based on the fitting of the positions of all reflections using HKL Scalepack [23]. Data integration and scaling of the reflections were performed with HKL Denzo and Scalepack [23]. Empirical multi-scan absorption corrections using equivalent reflections were performed with the SADABS program [24]. The structures of the compounds were solved 
by direct methods using the SHELXS program, and refinement was performed using SHELXL based on $F^{2}$ through the full-matrix least-squares routine [25]. All non-hydrogen atoms were refined with anisotropic displacement parameters. Hydrogen atoms were placed in calculated positions and refined isotropically using a riding model [26]. The $\mathrm{CF}_{3}$ groups are disordered over two positions, and fluorine atom occupancies were allowed to be refined freely. Due to large conformational disorder and to thermal motion present in $\mathrm{CF}_{3}$, large thermal displacement parameters were found for fluorine atoms. The $\mathrm{C}-\mathrm{F}$ bond length and $\mathrm{F}^{\cdots} \mathrm{F}$ separations were restrained to be equivalent using SADI command. The displacement parameters of disordered fluorine atoms were constrained to be the same using the EADP constraint. Details of data collection and structure refinement for 1-2 are summarized in Table 1. Table 2 shows selected bond lengths and angles in each complex, as well as important intermolecular contact parameters.

\section{Results and discussion}

For $\mathrm{L}=$ PyrNN and PyrIN, reaction with $\mathrm{Cu}(\mathrm{hfac})_{2}$ yields $\left[\mathrm{M}(\mathrm{hfac})_{2} \mathrm{~L}\right]$ complexes 1 and 2, respectively, as the only isolated crystalline products, even when a substantial excess of radical ligand is used, relative to the amount of $\mathrm{Cu}(\mathrm{hfac})_{2}$. Microanalysis indicates very good purity of the final products, without significant extra radical incorporation or other stoichiometry products. This is quite different from reactions of $\operatorname{PyrNN}$ with $\left[\mathrm{Mn}(\mathrm{hfac})_{2}\right]$ or $\left[\mathrm{Co}(\mathrm{hfac})_{2}\right]$, both of which can yield either $\left[\mathrm{M}(\mathrm{hfac})_{2} \mathrm{~L}_{2}\right]$ cluster complexes or $\left[\mathrm{M}(\mathrm{hfac})_{2} \mathrm{~L}\right]_{\mathrm{n}}$ chains depending on reactant ratio [16-17]. Copper(II) gives shorter $\mathrm{Cu}-\mathrm{O}$ bond lengths ( $1.9 \AA$ for equatorial ligands) compared to cobalt(II) $(\sim 2.0 \AA)$ and manganese(II) $(\sim 2.1-2.2 \AA)$ [27]. The shorter bonds make it harder to accommodate bulky ligands. The large steric requirements of PyrNN and PyrIN in $\mathbf{1}$ and $\mathbf{2}$ are therefore better accommodated in pentacoordinate instead of hexacoordinate ligand spheres. Also, as described below, pentacoordinate copper(II) in $\mathbf{1}$ or $\mathbf{2}$ forms additional novel, intramolecular close contacts 
with the pyrene $\pi$-electron cloud. Since conformational rotation of the radicals is expected in the solution phase during synthesis, the pyrene unit would sterically block approach of a second radical ligand that could give hexacoordinate copper(II). By comparison, Luneau, Rey, and coworkers found that reaction of $\mathrm{Cu}(\mathrm{tfac})_{2}(\mathrm{tfac}=$ trifluoroacetate $)$ with a simple phenyl-substituted $\mathrm{NN}$ or IN (PhIN) radical gives $\mathrm{CuL}_{2}$-type hexacoordinate octahedral complexes, with the radical units anti to one another [28]; here, both $\mathrm{PhIN}$ radicals were $\mathrm{Cu}$ $\mathrm{N}$ coordinated.

Compound 1 crystallizes in the $P-1$ space group with one independent $\left[\mathrm{Cu}(\mathrm{hfac})_{2}(\mathrm{PyrNN})\right]$ per unit cell. The copper(II) ion is pentacoordinated to four oxygen atoms from two $\mathrm{hfac}^{-}$groups $(\mathrm{O} 3, \mathrm{O} 4, \mathrm{O} 5$ and $\mathrm{O} 6)$, with the other position occupied by an aminoxyl oxygen atom (O1) of PyrNN (Figure 1); the other aminoxyl oxygen, O2, is not coordinated. In pentacoordinate compounds, the metal environment can be described on a continuum structure between square-pyramidal (SP) and trigonal-bipyramidal (TBP) extremes. The parameter $\tau$ has been used to describe the degree of structural distortion from the SP geometry $(\tau=0)$ to the TBP geometry $(\tau=1)$ [29]. For $\mathbf{1}, \tau=0.30$, indicating a distorted square pyramidal geometry for copper(II). The axial capping position is occupied by an hfac $\mathrm{O} 5$ atom, while the basal plane is formed by $\mathrm{O} 1, \mathrm{O} 3, \mathrm{O} 4$ and O6 atoms, with the copper(II) ion is $0.151 \AA$ out of the basal plane. As shown in Table 2, the capping Cu1-O5 bond length in 1 is longest by $0.15 \AA$, compared to the basal plane $\mathrm{Cu}-\mathrm{O}$ bonds. The coordinated PyrNN aminoxyl N1-O1 bond is a substantial, $0.044 \AA$ longer than the non-coordinated N2-O2 bond. Luneau and Rey reported analogous lengthening in the phenyl nitronyl nitroxide complex with $\mathrm{Cu}(\mathrm{tfac})_{2}$, and noted that greater lengthening of the coordinated $\mathrm{N}-\mathrm{O}$ bond is associated with stronger metal-radical magnetic exchange [28]. 


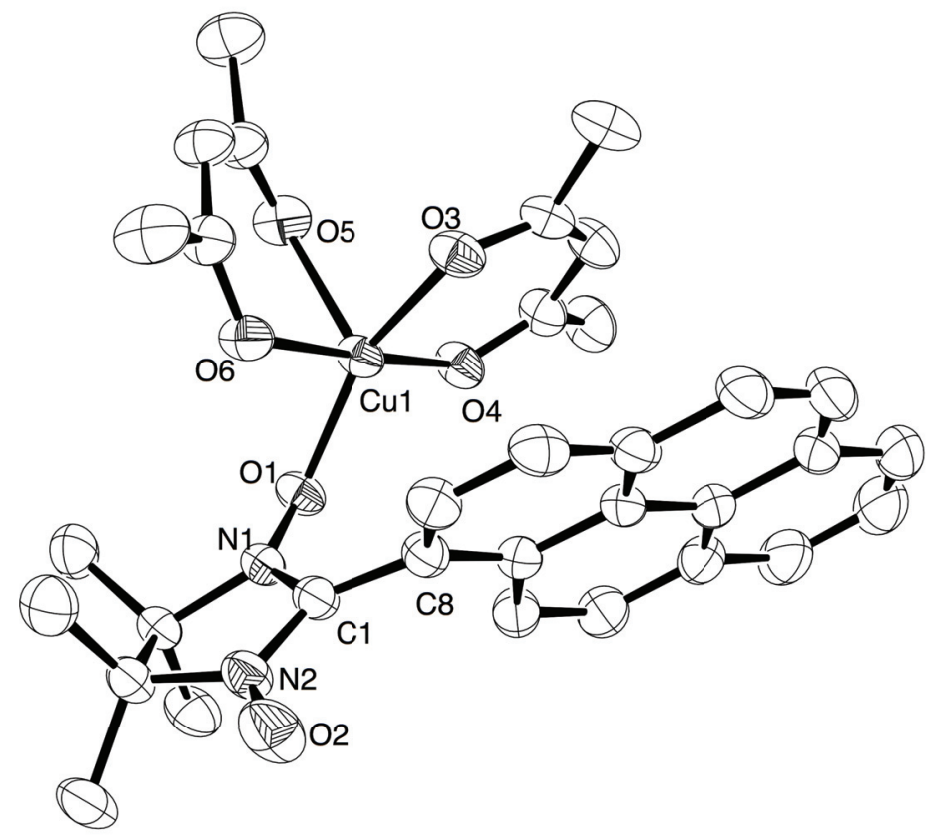

Figure 1: ORTEP view ( $30 \%$ probability) of the asymmetric unit of 1 . Hydrogen and fluorine atoms were omitted for the sake of clarity.

The five-atom nitronyl nitroxide unit $\mathrm{O} 1-\mathrm{N} 1-\mathrm{C} 1-\mathrm{N} 2-\mathrm{O} 2$ is essentially planar, allowing good spin delocalization among these atoms: this plane of the nitronyl nitroxide spin system is substantially twisted by $56.9^{\circ}$ relative to the pyrene ring. This amount of torsion is similar to that seen in the hexacoordinate 1:2 triad clusters and 1:1 chain complexes of PyrNN with $\left[\mathrm{Mn}(\mathrm{hfac})_{2}\right]$ and $\left[\mathrm{Co}(\mathrm{hfac})_{2}\right]$ [16-17]. In all of these, as well as in 1 (and 2, below), the "hinge" pyrene unit conformation $\mathrm{Cu}(\mathrm{II})-\mathrm{NN}-\mathrm{Pyr}$ always puts the metal ion and pyrene syn around the NN, so the pyrene unit is close to the metal ion, rather than extending away from the coordination sphere. 
Table 1: Crystal data and structure refinement for $\mathbf{1}$ and $\mathbf{2}$.

\begin{tabular}{|c|c|c|}
\hline Identification & (1) & (2) \\
\hline Formula & $\mathrm{C}_{33} \mathrm{H}_{23} \mathrm{CuF}_{12} \mathrm{~N}_{2} \mathrm{O}_{6}$ & $\mathrm{C}_{33} \mathrm{H}_{23} \mathrm{CuF}_{12} \mathrm{~N}_{2} \mathrm{O}_{5}$ \\
\hline $\mathrm{FW}_{\mathrm{W}}\left(\mathrm{g} \mathrm{mol}^{-1}\right)$ & 835.07 & 819.08 \\
\hline $\mathrm{T}(\mathrm{K})$ & 293(2) & 293(2) \\
\hline$\lambda(\AA)$ & 0.71073 & 0.71073 \\
\hline Crystal system & Triclinic & Triclinic \\
\hline Space group & $P-1$ & $P-1$ \\
\hline $\mathrm{a}(\AA)$ & $10.7249(2)$ & $10.3248(2)$ \\
\hline $\mathrm{b}(\AA)$ & $11.9776(2)$ & $12.5418(2)$ \\
\hline $\mathrm{c}(\AA)$ & $15.7412(3)$ & $14.3044(3)$ \\
\hline$\alpha$ (Deg, $)$ & $95.5380(10)$ & $79.8270(11)$ \\
\hline$\beta$ (Deg, $)$ & $96.5920(10)$ & $74.7940(10)$ \\
\hline$\gamma($ Deg, $)$ & $116.5360(10)$ & $86.0140(10)$ \\
\hline Volume $\left(\AA^{3}\right)$ & $1772.09(6)$ & $1758.82(6)$ \\
\hline Z & 2 & 2 \\
\hline$\rho_{\text {calc }}\left(\mathrm{Mg} \mathrm{m}^{-3}\right)$ & 1.565 & 1.547 \\
\hline$\mu\left(\mathrm{mm}^{-1}\right)$ & 0.725 & 0.727 \\
\hline $\mathrm{F}(000)$ & 840 & 824 \\
\hline$\theta$ range $\left(^{\circ}\right)$ & $2.63-27.58$ & $2.40-27.58$ \\
\hline Index ranges & $-13 \leq h \leq 13$ & $-13 \leq \mathrm{h} \leq 13$ \\
\hline & $-15 \leq k \leq 15$ & $-16 \leq \mathrm{k} \leq 16$ \\
\hline & $-20 \leq l \leq 20$ & $-18 \leq 1 \leq 18$ \\
\hline Data collected & 53971 & 43812 \\
\hline Independent reflections & 8172 & 8086 \\
\hline $\mathrm{R}_{\text {int }}$ & 0.0259 & 0.0245 \\
\hline Refinement method & \multicolumn{2}{|c|}{ Full-matrix least-squares on $F^{2}$} \\
\hline Data / restraints / parameters & $8172 / 144$ / 507 & 8086 / $206 / 508$ \\
\hline GOF on $F^{2}$ & 1.083 & 1.033 \\
\hline $\mathrm{R} 1, \mathrm{wR} 2[\mathrm{I}>2 \sigma(\mathrm{I})]$ & $0.0495,0.1451$ & $0.0494,0.1440$ \\
\hline R1,wR2 (all ) & $0.0603,0.1611$ & $0.0592,0.1561$ \\
\hline$\Delta \rho_{\max }, \Delta \rho_{\min }\left(\mathrm{e} \cdot \AA^{-3}\right)$ & $0.656,-0.555$ & $0.576,-0.552$ \\
\hline
\end{tabular}

But, in $\mathbf{1}$ (and 2, below), the syn-type metal to pyrene contact is especially and unusually close. The pyrene unit in $\mathbf{1}$ is folded directly under and nearly parallel to the basal plane formed by $\mathrm{Cu} 1$ with $\mathrm{O} 1 / \mathrm{O} 3 / \mathrm{O} 4 / \mathrm{O} 6$. This could be an electrophilic effect of the copper(II) ion interacting with the pyrene $\pi$-electron cloud, and/or a crystallographic density-optimizing effect putting the large pyrene unit in a sterically-accommodating region below the basal plane. The intramolecular metal to pyrene nonbonded contact distance $\mathrm{Cu} 1 \cdots \mathrm{C} 8$ is only $3.067(3) \AA$, essentially in van der Waals contact. So, although 1 is a distorted SP structure based only on metal to heteroatom coordination, the pyrene 
unit acts as a second capping site trans to the $\mathrm{Cu} 1-\mathrm{O} 5$ cap. The $\mathrm{Cu} 1-\mathrm{O} 5$ bond is the longest in the copper(II) coordination sphere at 2.225(2) $\AA$, so one can consider the pyrene as being pseudo-axial as well. The basal-coordinated PyrNN radical units can then be considered to be coordinated in a pseudo-equatorial environment. This is a useful viewpoint to consider magnetic behavior of the complexes, as described below.

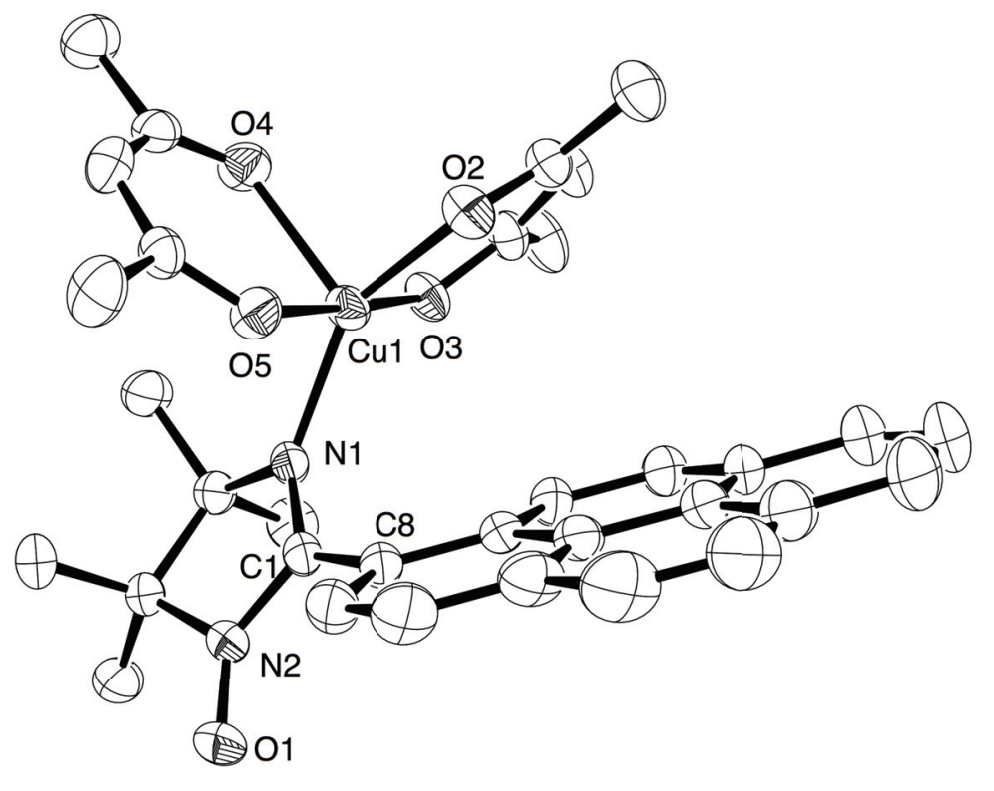

Figure 2: ORTEP view (30\% probability) of the asymmetric unit of 2. Hydrogen and fluorine atoms were omitted for the sake of clarity.

Compound 2 has similar structure to $\mathbf{1}$, with one independent $\left[\mathrm{Cu}(\mathrm{hfac})_{2}(\mathrm{PyrIN})\right]$ per unit cell. The copper(II) ion is pentacoordinated with four oxygen atoms from two hfac $^{-}$groups (O3, O4, O5 and O6), and the nitrogen atom (N1) of the PyrIN radical (Figure 2). This structure is one of the fairly rare examples of monodentate imino nitroxide aza-coordination on copper(II) [28,30-35]; most copper(II) imino nitroxide complexes involve bidentate radicals. The few monodentate imino nitroxide copper(II) complexes typically are part of chains or clusters[30-35], with the earlier-mentioned $\mathrm{Cu}(\mathrm{PhIN})_{2}$ complex[28] being one of the structurally simplest. Thus, complex 2 appears to be the first $1: 1, \mathrm{Cu}(\mathrm{II})$-L type complex of an imino nitroxide. The calculated parameter $\tau=0.51[29]$ indicates the copper(II) environment to be intermediate between idealized 
SP and TBP geometries. Similarly to $\mathbf{1}, \mathbf{2}$ has its pyrene unit conformationally rotated to lie roughly below the pseudo-trigonal basal unit formed by $\mathrm{Cu} 1$ with $\mathrm{O} 2$ and $\mathrm{O} 3$; unlike the case in $\mathbf{1}$, this basal unit and the pyrene form a more open bite angle in $\mathbf{2}$, due to a lack of "hinge" flexibility for the Cu1-N1 coordination compared to the Cu1-O1-N1 coordination in $\mathbf{1}$. The closest non-bonding metal to pyrene contacts in $\mathbf{2}$ are from $\mathrm{Cu} 1$ to $\mathrm{C} 8, \mathrm{C} 20$, and $\mathrm{C} 21$, at 3.279(3), 3.271(3), and 3.370(3) $\AA$, respectively. These are all somewhat longer than in $\mathbf{1}$, in a canted geometry relative to the basal plane that gives less favorable contact of copper(II) with the pyrene $\pi$-electron cloud. Still, the similar geometries of $\mathbf{1}$ and $\mathbf{2}$ suggest similar non-bonding interactions.

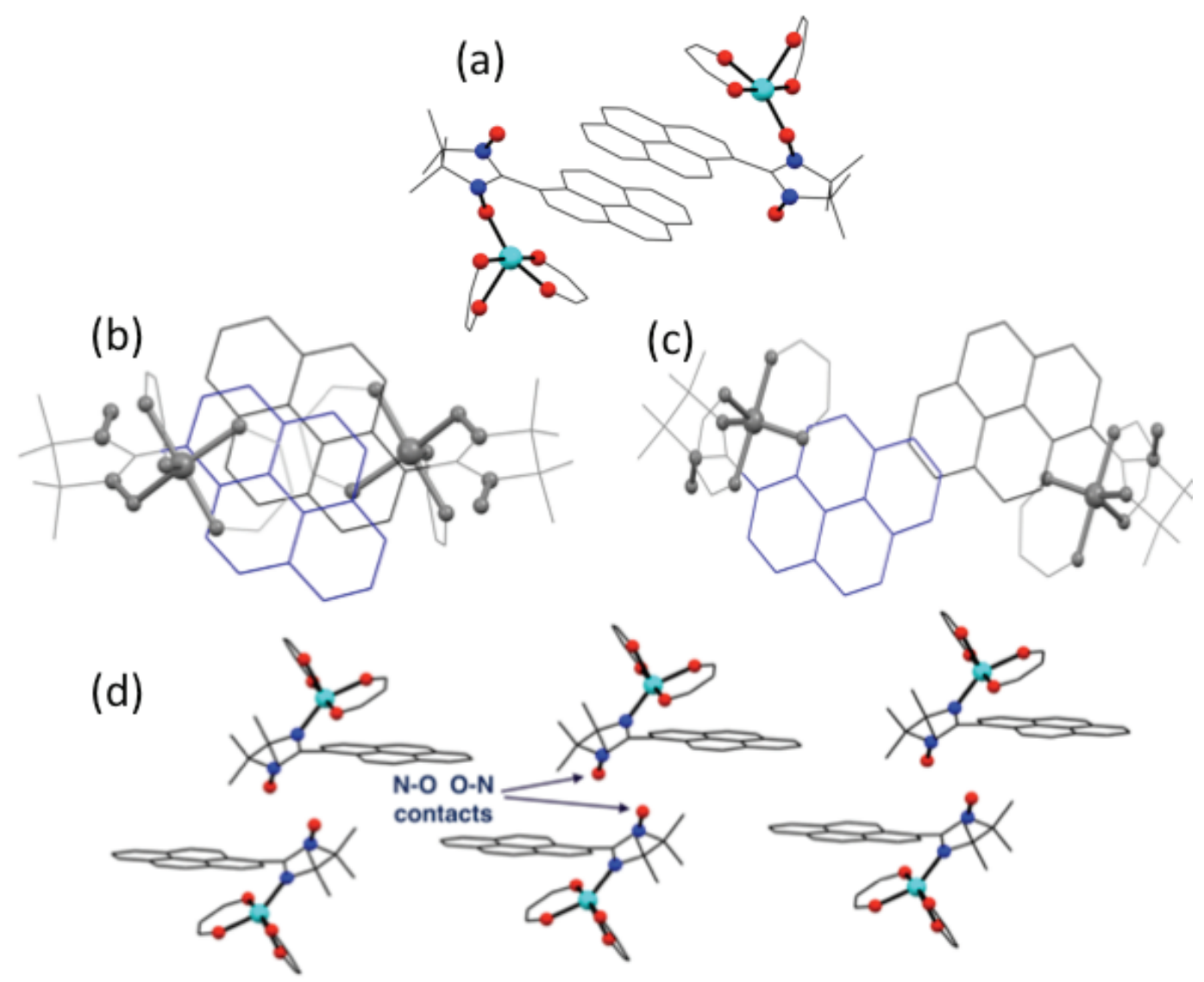

Figure 3: (a) Crystal packing showing pyrene-pyrene $\pi$-stacked dyads of 1; (b) view along the direction normal to the pyrene ring highlighting pyrene-pyrene slipped $\pi$ stacking for 1; (c) view analogous to (b) for 2; (d) crystal packing of 2 showing slipped $\pi$ stacking and intermolecular contacts between oxygen atoms (red spheres) of $\mathrm{N}-\mathrm{O}$ groups. 
Table 2: Selected bond lengths $(\AA)$, bond angles (degrees), and selected intermolecular contacts $(\AA)$ for $\mathbf{1}$ and $\mathbf{2}$.

\begin{tabular}{|c|c|c|c|}
\hline \multicolumn{2}{|c|}{1} & 2 & \\
\hline \multicolumn{4}{|c|}{ Bond lengths } \\
\hline $\mathrm{Cu} 1-\mathrm{O} 1$ & $1.9477(16)$ & $\mathrm{Cu} 1-\mathrm{O} 2$ & $1.997(2)$ \\
\hline $\mathrm{Cu} 1-\mathrm{O} 3$ & $1.9529(18)$ & $\mathrm{Cu} 1-\mathrm{O} 3$ & $1.934(2)$ \\
\hline $\mathrm{Cu} 1-\mathrm{O} 4$ & $1.9400(17)$ & $\mathrm{Cu} 1-\mathrm{O} 4$ & $2.151(2)$ \\
\hline $\mathrm{Cu} 1-\mathrm{O} 5$ & $2.225(2)$ & $\mathrm{Cu} 1-\mathrm{O} 5$ & $1.941(2)$ \\
\hline $\mathrm{Cu} 1-\mathrm{O} 6$ & $1.9445(17)$ & $\mathrm{Cu} 1-\mathrm{N} 1$ & $2.006(2)$ \\
\hline \multicolumn{4}{|c|}{ Bond angles } \\
\hline $\mathrm{O} 1-\mathrm{Cu} 1-\mathrm{O} 3$ & $157.76(8)$ & $\mathrm{O} 2-\mathrm{Cu} 1-\mathrm{N} 1$ & $146.89(10)$ \\
\hline $\mathrm{O} 4-\mathrm{Cu} 1-\mathrm{O} 1$ & $88.31(7)$ & $\mathrm{O} 3-\mathrm{Cu} 1-\mathrm{N} 1$ & $92.28(9)$ \\
\hline $\mathrm{O} 1-\mathrm{Cu} 1-\mathrm{O} 5$ & $111.05(8)$ & $\mathrm{N} 1-\mathrm{Cu} 1-\mathrm{O} 4$ & $116.42(9)$ \\
\hline $\mathrm{O} 6-\mathrm{Cu} 1-\mathrm{O} 1$ & $92.88(7)$ & $\mathrm{O} 5-\mathrm{Cu} 1-\mathrm{N} 1$ & $89.03(10)$ \\
\hline $\mathrm{O} 4-\mathrm{Cu} 1-\mathrm{O} 3$ & $92.02(7)$ & $\mathrm{O} 3-\mathrm{Cu} 1-\mathrm{O} 2$ & $91.75(9)$ \\
\hline $\mathrm{O} 3-\mathrm{Cu} 1-\mathrm{O} 5$ & $91.19(8)$ & $\mathrm{O} 2-\mathrm{Cu} 1-\mathrm{O} 4$ & $96.52(10)$ \\
\hline $\mathrm{O} 6-\mathrm{Cu} 1-\mathrm{O} 3$ & $88.49(8)$ & $\mathrm{O} 5-\mathrm{Cu} 1-\mathrm{O} 2$ & $88.30(10)$ \\
\hline $\mathrm{O} 4-\mathrm{Cu} 1-\mathrm{O} 5$ & $88.57(8)$ & $\mathrm{O} 3-\mathrm{Cu} 1-\mathrm{O} 4$ & $88.44(9)$ \\
\hline $\mathrm{O} 4-\mathrm{Cu} 1-\mathrm{O} 6$ & $175.56(8)$ & $\mathrm{O} 3-\mathrm{Cu} 1-\mathrm{O} 5$ & $177.52(9)$ \\
\hline $\mathrm{O} 6-\mathrm{Cu} 1-\mathrm{O} 5$ & $87.01(7)$ & $\mathrm{O} 5-\mathrm{Cu} 1-\mathrm{O} 4$ & $89.09(9)$ \\
\hline \multicolumn{4}{|c|}{ Other interatomic contacts } \\
\hline $\mathrm{Cu} 1 \cdots \mathrm{C} 8^{*}$ & $3.067(3)$ & $\mathrm{Cu} 1 \cdots \mathrm{C} 8 *$ & $3.279(3)$ \\
\hline & & $\mathrm{Cu} 1 \cdots \mathrm{C} 20^{*}$ & $3.271(3)$ \\
\hline & & $\mathrm{Cu} 1 \cdots \mathrm{C} 21^{*}$ & $3.370(3)$ \\
\hline \multirow[t]{2}{*}{$\begin{array}{l}\text { pyrene } \cdots \text { pyrene }^{i} \\
\text { (plane-to-plane) }\end{array}$} & 3.49 & $\begin{array}{l}\text { pyrene } \cdots \text { pyrene }^{i i} \\
\text { (plane-to-plane) }\end{array}$ & 3.34 \\
\hline & & $\mathrm{N} 2-\mathrm{O} 1 \cdots \mathrm{O} 1^{i i}$ & $3.099(4)$ \\
\hline
\end{tabular}

*Intramolecular metal-pyrene distance.

${ }^{i} 2-x, 1-y,-z$; intermolecular contact. ${ }^{i i}-x,-y, 1-z$; intermolecular contact.

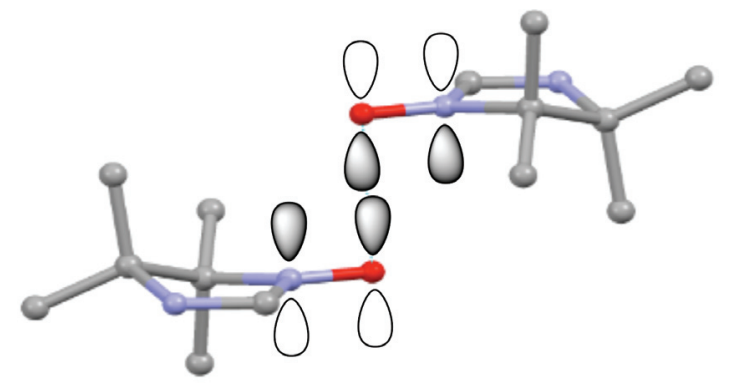

Scheme 2: Intermolecular, end-to-end SOMO-SOMO overlap between noncoordinated aminoxyl units in 2. Imino nitroxide unit geometries from the crystallographic structure.

Regarding intermolecular contacts in the crystal lattices, both $\mathbf{1}$ and $\mathbf{2}$ form solid state dyads through cofacial pyrene-pyrene $\pi$-stacking about a site of inversion symmetry, with 
the rest of the copper(II) coordination spheres on opposite faces (Figure 3). For 1, the pyrene rings are coplanar at an averaged plane-plane distance of $3.49 \AA$ (all pyrene carbon atoms averaged to form the plane). The average centroid-to-centroid distance is $3.96 \AA$ : the angle between the vector normal to the pyrene and the vector for the centroid-centroid distance is $28.3^{\circ}$, giving a $1.88 \AA$ ring slippage. For 2 , the pyrenes are also coplanar at a averaged plane-plane distance of $3.34 \AA$ but substantially slip-stacked and offset, such that the $\mathrm{H}-\mathrm{C}$ bonds of one pyrene are above the $\pi$-cloud of the other pyrene in the dyad (Figure $3 \mathrm{c}$ ). The closest $\mathrm{C}^{\cdots} \mathrm{C}$ contacts between pyrene units in $\mathbf{2}$ are $\sim 3.5 \AA$, with a centroid-to-centroid distance of $4.10 \AA$. Overall, the pyrene units provide an important organizational influence on crystal packing in 1-2, by forming dyad inter-pyrene contacts.

The pyrene $\pi$-stacking here is not expected to influence magnetic behavior directly, since the radical nitroxide spin density is not significantly delocalized onto the pyrene ring in PyrNN or PyrIN [19], and is not expected to do so in $\mathbf{1}$ or 2. This stacking clearly is an important crystal organization tendency here. Some analogy may be considered to multicenter, solid state inter-radical interactions that include so-called pancake bonding [36-38], interaction between oligoviologens radical[39-40] and also long bonds [41-42], which have drawn increasing scrutiny at the boundary between non-bonding and bonded. However, the pyrene-stack contacts in 1-2 do not involve sites of significant unpaired spin density, and so do not provide effective electronic mechanisms for such long-bond type interactions.

Complex 1 has no contacts of $<5 \AA$ between major spin density sites of the nitronyl nitroxide unit, although the uncoordinated $\mathrm{N}-\mathrm{O}$ unit forms close contacts with $\mathrm{C}-\mathrm{H}$ bonds of a neighboring pyrene unit. Since the pyrene fragment is expected to lack spin significant spin density as mentioned earlier, no strong inter-complex exchange is expected. But, in complex 2 the uncomplexed $\mathrm{N}-\mathrm{O}$ units form dyad pairs related by inversion symmetry, giving close contact between aminoxyl oxygen atoms (Figure $3 \mathrm{~d})$ with $\mathrm{r}\left(\mathrm{N}-\mathrm{O} 1 \cdots{ }^{\mathrm{ii}} \mathrm{O} 1-\mathrm{N}\right)=$ 3.099(4) A. These $\mathrm{N}-\mathrm{O} \cdots \mathrm{O}-\mathrm{N}$ contacts are in a geometry to give excellent end-to-end 
SOMO-SOMO (Singly-Occupied Molecular Orbital) overlap between high spin density sites (Scheme 2), appropriate to favor strong spin-pairing intermolecular exchange.

Notably, even at low temperatures dc magnetic susceptibility measurements for $\mathbf{1}$ show only minor paramagnetic susceptibility, attributable to quite small amounts of impurity spins. This behavior is consistent with very strong intramolecular copper(II)radical AFM interaction in 1. In copper(II) complexes with nitroxide-type radicals, either ferromagnetic (FM) or antiferromagnetic (AFM) metal-radical interaction can be observed depending on the coordination geometry. FM interactions are usually observed when the radical is axial coordinated by copper(II) [1-3,43], while strong AFM interactions are observed [44-46] when the radical is equatorial coordinated. Strong AFM intramolecular exchange is consistent with the observed short $\mathrm{Cu} 1-\mathrm{O} 1$ bond length of $1.95 \AA$ and the different $\mathrm{N}-\mathrm{O}$ bond lengths in $1[1-3,28]$. The observed AFM behavior supports considering the $\mathrm{Cu} 1-\mathrm{O} 1-(\mathrm{N})$ coordination as pseudo-equatorial, as described earlier.

The product of magnetic susceptibility with temperature $(\chi T)$ for 2 is $0.71 \mathrm{~cm}^{3}$ $\mathrm{mol}^{-1} \mathrm{~K}$ at $244 \mathrm{~K}$, smaller than expected $\left(0.81 \mathrm{~cm}^{3} \mathrm{~mol}^{-1} \mathrm{~K}\right)$ for a non-interacting system containing copper(II) and one radical with $g$ values equal to 2.15 and 2.00 , respectively. Upon cooling, $\chi T$ decreases to $0.09 \mathrm{~cm}^{3} \mathrm{~mol}^{-1} \mathrm{~K}$ at $2.0 \mathrm{~K}$, indicating dominant AFM interactions (Figure 4). We were able to fit the magnetic susceptibility using a model described by Eq. 1, having an intramolecular copper(II)-radical magnetic interaction $J_{1}$ with intermolecular exchange interaction $J_{2}$, and $S_{C u 1}=S_{C u 2}=S_{R I}=S_{R 2}=1 / 2$. To prevent overparametrization, a single $g$-value fixed at 2.1 was used as an appropriate value intermediate between $g$-values for copper(II) ion and a radical.

$$
\hat{H}=-2 J_{1}\left(S_{C u 1} \cdot S_{R 1}+S_{C u 2} \cdot S_{R 2}\right)-2 J_{2}\left(S_{R 1} \cdot S_{R 2}\right)+g \mu_{B} B\left[\dot{S}_{R 1}+\dot{S}_{R 2}+\dot{S}_{C u 1}+\dot{S}_{C u 2}\right](E q .1)
$$


The best fit parameters for 2 obtained from the Fig. 4 data using this model were $2 J_{1}=151 \mathrm{~cm}^{-1}$ and $2 J_{2}=-220 \mathrm{~cm}^{-1}$. The intramolecular FM interaction $J_{1}$ is in the range observed in similar systems [28,30-35]. Since no increase of $\chi T$ occurred as temperature decreases, multiple fits were attempted while assuming both $J_{1}$ and $J_{2}$ to be AFM; however, these gave no satisfactory result. Previous work for imino-coordinated copper(II) imino nitroxide complexes attribute the ferromagnetic interactions to orthogonality between the metal magnetic orbital and the $\pi^{*}$ magnetic orbital of the radical $[28,47]$. And, similarly to our case, $\chi T$ often does not increase as temperature decreases for other FM coupled copper(II)-imino nitroxide compounds, due to the occurrence of strong AFM intermolecular magnetic interactions. Such intermolecular spin-pairing occurs through close $\mathrm{NO}^{\cdots} \mathrm{NO}$ contacts giving SOMO-SOMO interactions [1-2,28], like those in Scheme 2 arising from the crystallography of $\mathbf{2}$. Finally, the strong AFM magnetic interaction found for $J_{2}$ is also in good agreement with behavior for PyrIN itself, which can crystallize with short, dimeric spin-pairing NO ${ }^{\cdots} \mathrm{NO}$ contacts [19].

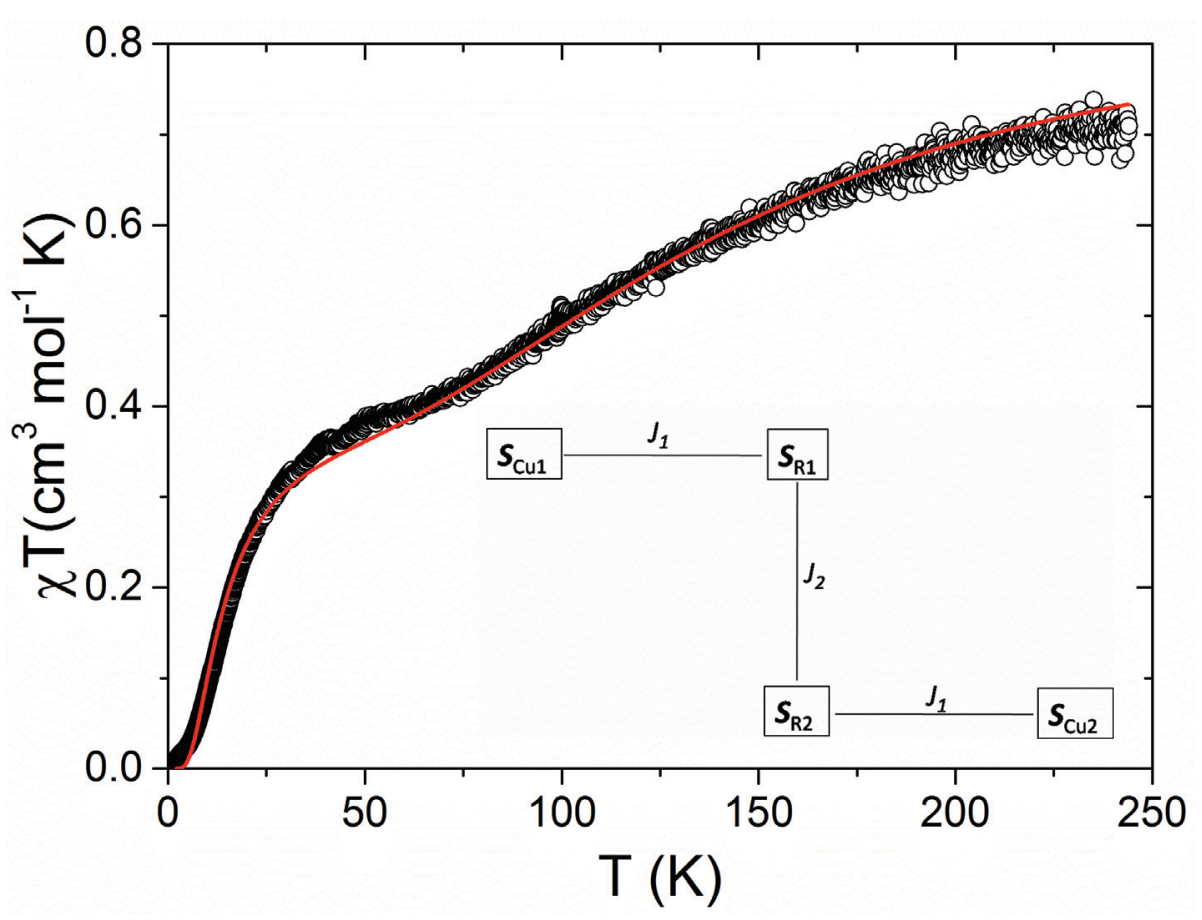


Figure 4: Temperature dependence of $\chi T$ for 2 . The solid line represents the best fit using Eq.1. Inset: spin topology model used to fit the magnetic data.

The powder X-band electron paramagnetic resonance (EPR) spectra for both 1-2 at 293 and $77 \mathrm{~K}$ show only symmetric, very weak signals with $g=2.006$ and linewidth $\approx$ $16 \mathrm{G}$ that are attributable to small radical paramagnetic impurities. There are no detectable copper(II) EPR transitions at either temperature. The lack of an EPR signal in $\mathbf{1}$ is attributable to a singlet ground state due to strong antiferromagnetic metal-radical spin-pairing, consistent with its short $1.95 \AA \mathrm{Cu} 1-\mathrm{O} 1(\mathrm{~N} 1)$ bond and the large difference between its coordinated and non-coordinated aminoxyl bond lengths. The spin-pairing must be intramolecular, due to the lack of intermolecular contacts between significant spin density sites in $\mathbf{1}$.

By comparison, numerous EPR spectra have been reported for copper(II) imino nitroxide complexes, with widely variable lineshapes due to wide variation in metal radical exchange. Some of them exhibit weak or no copper-related features in powder [30-31] or solution[48] EPR spectrum at room temperature. Such EPR silence has been attributed to unfavorable electron spin relaxation (solid) or large anisotropy in the molecules (solution) [30-31]. Presuming FM exchange in $\mathbf{2}$ from the magnetic studies, similar reasons would explain its lack of an observed EPR signal.

UB97D/6-31G* computations [49] were carried out using Gaussian 09[50] for singlet and triplet states using the crystallographic geometries of $\mathbf{1}$ and $\mathbf{2}$ to probe further their metal-radical exchange coupling and electronic structure. All $\mathrm{CF}_{3}$ groups were replaced by $\mathrm{CH}_{3}$, and radical $\mathrm{CH}_{3}$ groups replaced by hydrogen atoms. Singlet-state computations were carried out using broken symmetry wavefunctions. Yamaguchi's correction[51] was applied to the final energies, to adjust for spin-contamination effects. 
For 1, the computed triplet-singlet energy gap was $2 J=-213 \mathrm{~cm}^{-1}$, indicating signficant antiferromagnetic exchange. For $\mathbf{2}$, the analogous calculation gave ferromagnetic exchange with $2 J=610 \mathrm{~cm}^{-1}$. The computed exchange behaviors are consistent with the observed crystallographic and magnetic results; although calculated and experimental metalradical interactions for $\mathbf{2}$ differ quantitatively, they agree about the interaction being strong and FM in nature.

The calculated frontier molecular orbitals of $\mathbf{1 - 2}$ and their ground state Wiberg[52-54] bond order matrices were also examined. For both complexes, the bond orders between copper(II) and the closest contact carbon atoms in the pyrene units were not notably high at our level of theory. Both the frontier orbitals of singlet $\mathbf{1}$ and the singly-occupied molecular orbitals (SOMOs) of triplet 2 show small atomic orbital coefficients on all of the pyrene carbon atoms, with slight increases on those that are in closer proximity to the copper(II) ion. So, the metal to pyrene close contacts do not appear to arise from significant bonding interactions, and are probably best attributed to efficient space filling of the crystal lattice and/or favorable (though broadly distributed) Coulombic interactions between the copper(II) ion and the pyrene $\pi$-cloud.

\section{Conclusion}

Two new copper(II) compounds were synthesized, with pentacoordination involving nitronyl nitroxide and imino nitroxide radicals that bear a sterically substantial pyrene polycyclic aromatic hydrocarbon (PAH) pendant ring. Mononuclear copper(II) imino nitroxide complexes like $\mathbf{2}$, coordinated in monodentate fashion by the imino nitrogen atom, are unusual with few reported examples. Both complexes showed close nonbonded interactions between the copper(II) center and a conformationally syn-folded pyrene $\pi$ electron cloud. This is a novel interaction for metal-radical systems, since so few coordinated radical ligands incorporate a large PAH. A strong intramolecular copper(II)- 
radical AFM and FM exchange interaction was observed for $\mathbf{1}$ and $\mathbf{2}$, respectively. In addition, the pyrene units cause the molecular complexes to form dyads through PAH stacking in the solid state, an important controlling factor for solid state self-assembly. Both of the new complexes have uncomplexed radical unit sites, so they may be able in future work to serve as building blocks for extended solids through further coordination.

\section{Acknowledgements}

RAAC acknowledges CNPq (Brazil) for a fellowship that enabled portions of this work to be carried out at the University of Massachusetts Amherst. JRF thanks the U.S. National Science Foundation for support under grant $\mathrm{n}^{0}$ DMR-1310135; The authors acknowledge Prof. Luis Ghivelder from IF-UFRJ for use of laboratory facilities.

\section{References}

[1] A. Caneschi, D. Gatteschi , R. Sessoli, P. Rey, Acc. Chem. Res. 22 (1989) 392.

[2] A. Caneschi, D. Gatteschi, P. Rey, Prog. Inorg. Chem. (1991) 39. 
[3] P. Rey, V.I. Ovcharenko, Copper(II) Nitroxide Molecular Spin-Transition Complexes, J.S. Miller, M. Drillon, Magnetism: Molecules to Materials, volume 5 (2004) Wiley$\mathrm{VCH}$, Weinheim, Germany.

[4] L. Bogani, A. Vindigni, R. Sessoli, D. Gatteschi, J. Mater. Chem.18 (2008) 4750.

[5] S. Demir, I-R. Jeon, J.R. Long, T.D. Harris, Coord. Chem. Rev. 289-290 (2015) 149.

[6] I. Ratera, J. Veciana, Chem. Soc. Rev. 41 (2012) 303

[7] D.J.R. Brook, Comments Inorg.Chem. 35 (2015) 1.

[8] G. N. Lipunova, T. G.Fedorchenko, O. N. Chupakhin, Russ. Chem. Rev. 82 (2013) 701.

[9] K. E. Preuss, Coord. Chem. Rev. 289-290 (2015) 49.

[10] I. S. Morgan, A. Mansikkamäki, G. A. Zissimou, P. A. Koutentis, M. Rouzières, R. Clérac, H. M. Tuononen, Chem. Eur. J. 21 (2015) 15843

[11] I. S. Morgan, A. Peuronen, M. M. Hänninen, R. W. Reed, R. Clérac, H. M. Tuononen, Inorg. Chem. 53 (2014) 33.

[12] S. Fortier, J. J. Le Roy, C-H Chen, V. Vieru, M. Murugesu, L. F. Chibotaru, D. J. Mindiola, K. G. Caulton, J. Am. Chem. Soc. 135 (2013) 14670

[13] J. S. Miller, Chem. Soc. Rev. 40 (2011) 3266

[14] D. A. Shultz, in Miller, J. S., Drillon, M., (Eds.), Magnetism: Molecules to Materials II: Molecule-Based Materials; Wiley-VCH: Weinheim, 2002, pp. 281-304.

[15] A. Witt, F. W. Heinemann, M. M. Khusniyarov, Chem. Sci. 6 (2015) 4599

[16] M.G.F. Vaz, R. A. Allão, H. Akpinar, J. A. Schlueter, S. Santos Jr., P. M. Lahti, M. A. Novak, Inorg. Chem. 51 (2012) 3138.

[17] M.G.F. Vaz, R.A.A. Cassaro, H. Akpinar, J.A. Schlueter, P.M. Lahti, M.A. Novak, Chem. Eur. J. 20 (2014) 5460.

[18] R.A.A. Cassaro, S.G. Reis, T.S. Araujo, P.M. Lahti, M.A. Novak, M.G.F. Vaz, Inorg. Chem. 54 (2015) 9381.

[19] H. Akpinar, J.T. Mague, M.A. Novak, J.R. Friedman, P.M. Lahti, CrystEngComm 14 (2012) 1515.

[20] P. Pascal, Ann. Chim. Phys. 19 (1910) 5. 
[21] O. Kahn, Molecular Magnetism, Wiley-VCH, Weinheim, 1993.

[22] R. T. Azuah, L. R. Kneller, Y. Qiu, P. L. W. Tregenna-Piggott, C. M. Brown, J. R. D. Copley, R. M. Dimeo, J. Res. Natl. Inst. Stand. Technol. 114 (2009) 341.

[23] Z. Otwinowski, W. Minor, Methods in Enzymology, Macromolecular Crystallography, part A.C.W. Carter, Jr. \& R.M. Sweet, Eds., Academic, 1997, Volume 276, pp. 307-326. [24] SADABS, Bruker Analytical X-ray Systems, Inc., Madison WI, 1997.

[25] G.M. Sheldrick, Acta Cryst. A64 (2008) 112.

[26] C.K. Johnson, in: F.R. Ahmed (Ed.), Crystallographic Computing, Munksgaard, Copenhagen, Denmark, 1970, pp 207-219.

[27] M. Nayak, R. Koner, H-H Lin, U. Florke, H-H. Wei, S. Mohanta, Inorg. Chem. 45 (2006) 10764.

[28] A. Cogne, J. Laugier, D. Luneau, P. Rey, Inorg. Chem. 39 (2000) 5510.

[29] A.W. Addison, T. Nageswara, J. Reedijk, J. van Rijn, G.C. Verschoor, J. Chem. Soc., Dalton Trans. (1984) 1349.

[30] D. Luneau, F. M. Romero, J. Laugier, P. Fires, A. Caneschi, D. Gatteschi, R. Sessoli, J. Am. Chem. Soc. 113 (1991) 1245.

[31] F. Lanfranc de Panthou, D. Luneau, R. Musin, L. Ohrstrom, A. Grand, P. Turek, P. Rey, Inorg. Chem. 35 (1996) 3484.

[32] T. Ise, T. Ishida, T. Nogami, Bull. Chem. Soc. Jpn. 75 (2002) 2463.

[33] S.V. Fokin, G.V. Romanenko, Yu.G. Shvedenkov, V.N. Ikorskii. S.F. Vasilevsky, E.V. Tret'yakov, V.I. Ovcharenko, Zh. Strukt. Khim. 43 (2002) 891.

[34] O.V. Koreneva, G.V. Romanenko, V.I. Ovcharenko, Zh. Strukt. Khim. 45 (2004) 357.

[35] S. Suzuki, N. Itoh, K. Furuichi, M. Kozaki, D. Shiomi, K. Sato, T. Takui, H. Ohi, S. Itoh, K. Okada, Chem. Lett. 40 (2011) 22.

[36] K. E. Preuss, Polyhedron 79 (2014) 1.

[37] H. Z. Beneberu, Y-H. Tian, M. Kertesz, Phys. Chem. Chem. Phys. 14 (2012) 10713 
[38] Z-h. Cui, A. Gupta, H. Lischka, M. Kertesz, Phys. Chem. Chem. Phys. 17 (2015) 23963.

[39] Y. Wang, M. Frasconi, W-G Liu, Z. Liu, A. A. Sarjeant, M. S. Nassar, Y. Y. Botros, W. A. Goddard, J. F. Stoddart, J. Am. Chem. Soc. 137 (2015) 876.

[40] A. Trabolsi, N. Khashab, A. C. Fahrenbach, D. Friedman, M. T. Colvin, K. K. Cotí, D. Benítez, E. Tkatchouk, J-C. Olsen, M. E. Belowich, R. Carmielli, H. A. Khatib, W. A. Goddard III, M. R. Wasielewski, J. F. Stoddart, Nat. Chem. 2 (2010) 42.

[41] J. S. Miller, Chem. Eur. J. 21 (2015) 9302.

[42] A. G. Graham, F. Mota, E. Shurdha, A. L. Rheingold, J. J. Novoa, J. S. Miller, Chem. Eur. J. 21 (2015) 13240.

[43] A. Caneschi, D. Gatteschi, A. Grand, J. Laugier, L. Pardi, P. Rey, Inorg. Chem. 27 (1988) 1031.

[44] Y.Y. Lim, R.S. Drago, Inorg. Chem. 11 (1972) 1334.

[45] D. Gatteschi, J. Laugier, P. Rey, C. Zanchini, Inorg. Chem. 26 (1987) 938.

[46] R.N. Musin, P.V. Schastnev, S.A. Malinovskaya, Inorg. Chem. 31 (1992) 4118.

[47] R. N. Musin, V.I. Ovcharencko, L. Ohrstrom, P. Rey, J. Struct. Chem. 38 (1997) 703.

[48] P. F. Richardson, R. W. Kreilick, J. Magn. Reson. 29 (1978) 285

[49] S. Grimme, S. Ehrlich, L. J. Goerigk, J. Comp. Chem. 32 (2011) 1456-65.

[50] Gaussian 09, Revision B.01; M. J. Frisch, G. W. Trucks, H. B. Schlegel, G. E. Scuseria, M. A. Robb, J. R. Cheeseman, G. Scalmani, V. Barone, B. Mennucci, G. A. Petersson, H. Nakatsuji, M. Caricato, X. Li, H. P. Hratchian, A. F. Izmaylov, J. Bloino, G. Zheng, J. L. Sonnenberg, M. Hada, M. Ehara, K. Toyota, R. Fukuda, J. Hasegawa, M. Ishida, T. Nakajima, Y. Honda, O. Kitao, H. Nakai, T. Vreven, J. A. Montgomery, Jr., J. E. Peralta, F. Ogliaro, M. Bearpark, J. J. Heyd, E. Brothers, K. N. Kudin, V. N. Staroverov, T. Keith, R. Kobayashi, J. Normand, K. Raghavachari, A. Rendell, J. C. Burant, S. S. Iyengar, J. Tomasi, M. Cossi, N. Rega, J. M. Millam, M. Klene, J. E. 
Knox, J. B. Cross, V. Bakken, C. Adamo, J. Jaramillo, R. Gomperts, R. E. Stratmann, O. Yazyev, A. J. Austin, R. Cammi, C. Pomelli, J. W. Ochterski, R. L. Martin, K. Morokuma, V. G. Zakrzewski, G. A. Voth, P. Salvador, J. J. Dannenberg, S. Dapprich, A. D. Daniels, O. Farkas, J. B. Foresman, J. V. Ortiz, J. Cioslowski, and D. J. Fox, Gaussian, Inc., Wallingford CT, 2010.

[51] K. Yamaguchi, Chem. Phys. Lett. 149 (1988) 537.

[52] K.B. Wiberg, Tetrahedron 24 (1968) 1083.

[53] I. Mayer, Chem. Phys. Lett. 97 (1983) 270.

[54] I. Mayer, Chem. Phys. Lett. 117 (1985) 396. 